\title{
IMPORTÂNCIA DO ESTUDO DAS VERTENTES
}

ANTONIO J. G. VELOSO

Universidade Federal Fluminense

Ainda que quase toda a superfície terrestre seja formada por encostas e a compreensão de suas formas e processos naturais atuando nelas seja fundamental para a Geomorfologia e a Engenharia, sua análise ambiental só recentemente começa a receber atenção dos vários profissionais envolvidos com o assunto. Podemos definir uma vertente simplesmente como um elemento da superfície terrestre inclinado em relação à horizontal. Desta maneira uma vertente possui um gradiente, dando uma direção ou orientação no espaço.

$\mathrm{O}$ fato de que muitas superfícies terrestres sejam inclinadas é muito relevante. A água das chuvas flui rapidamente pelas encostas mais escarpadas, tanto sobre o terreno, quanto se infiltrando no solo, e contribui para o movimento de partículas de rocha, solo, e material dissolvido. Se a vertente é bastante escamada, os materiais podem escorregar ou rolar sem a interferência de qualquer agente externo como, por exemplo, as águas correntes. Chamamos isto de processos de transporte nas encostas. Os processos de transporte retiram rochas ou pedaços do solo de um lugar (intemperismo), transportam-no a alguma distância abaixo da linha das vertentes mais íngremes e depositam-no de novo em outro local (erosão). Conforme ocorrem o intemperismo, o transporte e a deposição em outro local, a que denominamos erosão, a forma ou geometria das vertentes, e também de toda a superfície terrestre, e moldada nas paisagens que observamos. As encostas fornecem o poder original para estes processos que moldam as paisagens por permitir que a gravidade, que em geral atua verticalmente, atue com um componente lateral.

\section{ALGUNS TERMOS BÁSICOS:}

As vertentes são locais onde ocorrem o intemperismo, o transporte e deposição de materiais. $\mathrm{O}$ estudo das encostas e dos processos que nelas ocorrem requer uma descrição cuidadosa e precisa das encostas e geralmente é feita com referência ao seu perfil. O perfil da vertente é a linha traçada sobre o terreno descrevendo sua inclinação. Esta inclinação é expressa por um ângulo ou um gradiente e sua orientação é dada pelos pontos cardeais. Vertentes cujo perfil tem um ângulo constante são chamadas retilineares, segmentos ou partes das vertentes também podem ter este tipo de perfil. As vertentes curvas podem ser convexas ou côncavas de acordo com a direção da curvatura (fig 1) e não podem ser descritas por um simples ângulo, mas pelo grau de curvatura do segmento.

Para estudar as implicações em tempo longo ou curto torna-se necessária uma descrição cuidadosa da forma vertente. Em períodos curtos, de apenas alguns anos, não só o ângulo da vertente como em menor escala sua forma são influenciados e limitados pela atuação dos processos antrópicos e climáticos atuais. Em períodos de tempo mais longos, as vertentes são esculturadas por processos que atuam em períodos de tempo geológico. Há tendência das vertentes a atingir o perfil de equilíbrio com a atuação continuada dos processos nela atuantes. As formas de equilíbrio nos interessam porque uma vez que tenhamos entendido o relacionamento entre processos e forma poderemos explicar a paisagem de acordo com os processos que a originaram.

Devemos entender que embora praticamente toda a superfície terrestre seja afetada pelos processos das vertentes, são extremamente variáveis os graus de erosão e modificação da 
paisagem terrestre. Várias partes do nosso relevo se modificam muito lentamente ou até atingiram a estabilidade. Porém a maior parte do relevo do Estado do Rio de Janeiro está sendo erodido muito rapidamente e sua forma está sendo modificada constantemente, trazendo grandes problemas não só aos administradores, políticos e defesa civil mas também a toda a população, principalmente à de baixa renda. Isto não ocorre apenas nas áreas montanhosas, mas também nas regiões litorâneas, entre as quais: Atafona, Barra de S. João, Maricá, ilha Grande, onde temos realizado vários estudos e que se modificam de ano para ano.

\section{OBJETIVOS DO ESTUDO DAS VERTENTES}

Qual o objetivo de se estudar as encostas? A que profissionais interessa? Para o Geomorfólogo, as vertentes são unidades básicas do relevo e são fundamentais para explicar o desenvolvimento das paisagens. Desta maneira descrevem e explicam a sua evolução, baseados no sistema geoambiental sob observação. Porém, os estudos das vertentes têm uma abrangência muito mais ampla do que a explicação do relevo, em particular para a engenharia, defesa civil e agricultura.

A maioria dos projetos da engenharia civil, principalmente a construção de rodovias, está intimamente ligada às vertentes. Na sua construção, o gradiente dos taludes não deve exceder padrões aceitáveis na estabilidade das encostas a fim de que não ocorram deslizamentos ou escorregamentos, para tanto, nos cortes, deve ser diminuído ao máximo o ângulo do talude e evitados aterros. Desta maneira o aparecimento de ravinas e voçorocas é minimizado. Aliás os engenheiros civis, são os profissionais que mais tem contribuído para o conhecimento dos problemas das vertentes. Muitos dos equipamentos de campo e laboratório usados na classificação dos materiais e mecânica dos solos foram desenvolvidos pela engenharia civil. Além disso foram os engenheiros os responsáveis para que compreendêssemos os processos que atuam nas encostas, desenvolvendo as teorias mecânicas que explicam o comportamento dos solos e rochas das vertentes. Todavia o principal interesse do engenheiro nas vertentes é na praticabilidade do projeto e seu custo, através de uma análise detalhada das variáveis envolvidas no mesmo. Entretanto é um erro, cometido freqüentemente, analisar-se apenas o custo da construção sem se prever a manutenção. Temos observado todos os anos prejuízos enormes por interrupção do tráfego devido a quedas de barreiras ou voçorocamentos de aterros mal feitos ou inadequados. Embora mais caros, seria melhor construir um viaduto, mas ser uma obra definitiva.

Mecânica dos solos é uma disciplina científica que estuda o comportamento dos solos e rochas quando submetidos a estresse e é a base para analisar a estabilidade das vertentes, sendo importante tanto para o Engenheiro civil quanto o Geomorfólogo. Se a encosta é estável, não há tendência do solo ou rochas deslizarem. E simples analisar a estabilidade das encostas, basta fazer o cálculo de que forças são mais atuantes, as que tendem a causar os deslizamentos ou as que tendem a resistir a eles. O principal fator a determinar a resistência aos deslizamentos é a coesão do solo. Contudo para a engenharia civil o principal problema de estabilidade das vertentes é saber se haverá estabilidade após um corte ou um aterro realizados nelas.

Muitas vertentes naturais estão sujeitas a deslizamentos ou escorregamentos cujas formas são diretamente controladas pelos processos nelas atuantes. O Geomorfólogo que estuda a estabilidade das encosta deve usar métodos de controle de deslizamentos desenvolvidos pela engenharia civil. Entretanto, para os engenheiros as encostas naturais não são objeto de estudo, por isso deve haver trabalho de equipe com o Geomorfólogo que além de estudar os movimentos de massa ainda estuda os processos geomórficos e taxas de erosão que dão determinado formato à vertente.

\section{EROSÃO DO SOLO}

Geralmente dividimos a erosão do solo em duas categorias: Erosão Natural ou Geológica e erosão acelerada ou antrópica. A erosão geológica é aquela que ocorre em solos onde não 
houve interferência humana, não é considerado um problema mas parte essencial de evolução das paisagens naturais. Este tipo de erosão, junto com os processos de intemperismo, é responsável pela formação dos solos e em tempo geológico (milhões de anos) produziu todos os tipos de topografia hoje existentes. Sob condições de erosão natural, a formação de solo e a erosão desenvolveram através dos tempos os solos hoje existentes. A cobertura vegetal é de vital importância para a manutenção do estado de equilíbrio e qualquer alteração que nela se produza, tende a conduzir à erosão acelerada. As atividades que conduzem à erosão acelerada, são principalmente os desmatamentos para a agricultura, pecuária e construção civil. Ao dois principais fatores que levam à erosão acelerada são: as taxas de Erosividade e de erodibilidade.

Erosividade: é a capacidade das chuvas para causar erosão. Depende das características físicas da chuva como: intensidade total, tamanho das gotas e velocidade. Conhecendo estes fatores saberemos a energia cinética ou a totalidade do poder erosivo de determinada chuva.

Erodibilidade: é a vulnerabilidade ou susceptibilidade do solo à erosão, é função das características físicas do solo e do seu manejo. Enquanto que a erosividade é medida diretamente através dos parâmetros físicos da chuva, a erodibilidade é muito mais complexa porque depende de muito mais variáveis, porém os solos onde não houve atividade humana não apresentam erodibilidade. Deste modo este é um fenômeno causado por interferência humana e é essencial conhecermo-la para sabermos se e como devemos utilizá-lo.

Solos: São a zona de interação entre a Litosfera (Crosta sólida da Terra), a Atmosfera e a Biosfera, e são influenciados pela rocha matriz, pelo clima, a vegetação e a geometria das vertentes. Nas vertentes, os processos de intemperismo e erosão ocorrem sobre os solos e dentro dos mesmos. O conhecimento dos solos é fundamental para entendermos as vertentes, uma vez que existe uma interação entre ambos. Assim a geometria das vertentes influencia a tipo de solo, enquanto que as propriedades do solo, como espessura e estabilidade, influenciam o desenvolvimento das vertentes.

\section{FORÇAS QUE ATUAM NAS VERTENTES}

Em toda a superfície terrestre é muito raro termos a rocha nua aflorando. Assim quase todas as encostas são cobertas por alguma espécie de sedimento, que pode ser solo ou regolito, derivados do intemperismo da sua rocha matriz ou de materiais que para aí foram transportados. Contudo na maioria das vertentes ocorrem solos derivados da rocha matriz que jaz sob os mesmos. A forma de quase todas as encostas é do solo e do modo e velocidade com que ele se move. Todo o movimento de materiais, incluindo os solos, requer a aplicação de uma força. Uma força é uma ação que tende a modificar o estado de movimento de um corpo, isto é, se aplicarmos uma força a um objeto em repouso, tenderemos a fazê-lo se movimentar na direção na qual a força foi aplicada, se já estiver em movimento mudará de velocidade e possivelmente de direção. Nem sempre um corpo se movimentará ao aplicarmos uma força, pois somente há uma tendência a isso ocorrer.

A principal força que atua nas encostas é a gravidade, que é a atração mútua entre dois corpos. $\mathrm{Na}$ Terra os corpos tendem a ser atraídos verticalmente para seu centro. A força exercida sobre um objeto em repouso na superfície terrestre é mais ou menos igual ao seu peso. A gravidade pode atuar diretamente no movimento de algumas partículas sedimentares, como um pedaço de rocha que se desprenda de um bloco. Mas a maioria das vezes a gravidade atua em conjunto com outros agentes, principalmente as águas correntes. A gravidade causa o movimento da água pelas encostas, e por sua vez, esta exerce forças nas partículas sedimentares, tendendo a transportá-las.

A água exerce forças sobre o solo e dentro do solo, importantes nos processos de transporte. Um solo pode estar saturado ou insaturado pela água. Num solo saturado, onde os poros ou interstícios estão completamente preenchidos pela água, a qual exerce pressão tendendo a afastar uns dos outros os grãos dos sedimentos, resultando na perda completa da coesão do solo, provocando seu movimento. Num solo insaturado, onde seus poros não são completamente preenchidos pela água a força de sucção (tensão capilar) exercida tende a unir mais os grãos do solo, como observamos por exemplo nas areias da praia que só podem ser moldadas úmidas. 
Um outro conjunto de forças que atuam nas encostas são devidas à contração e expansão dos grãos do solo ou dos minerais das rochas, podemos classifica-las de forças climáticas, a amplitude térmica diária (diferença de temperatura entre noite e dia), essa expansão e contração faz com que os fragmentos de rochas e partículas do solo fluam pelas vertentes. Quando o solo tem presença de água que congela, este movimento é mais intenso.

As argilas presentes em maior ou menor quantidade em todos os solos, são talvez o fator mais importante nos movimentos de massa ocorridos no Brasil. As argilas são formadas por lâminas alternadas de sílica $(\mathrm{SiO} 2)$ e alumina $(\mathrm{Al}(\mathrm{OH}) 3)$ e podem absorver consideráveis quantidades de água entre estas lâminas. Ao atingir o limite de liquidez (passam a comportar-se como líquido) fluem pelas encostas.

Por último, as plantas e animais exercem forças sobre o solo, algumas muito importantes. Os animais, principalmente o gado, ajudam a compactar o solo podendo provocar a formação de ravinas e voçorocas, que muitas vezes começam onde um animal pisou com a pata, iniciando o processo. Além disso no caminho do pasto são os responsáveis pelos terraços que aceleram os processos.

\section{MOVIMENTOS DE MASSA}

Dentre os fenômenos que envolvem a retirada de grande quantidade de materiais, podemos incluir a subsidência de minas e galerias, porém nos interessam apenas os processos ocorridos nas encostas, e podem ocorrer tanto em encostas naturais quanto nas artificiais ou antrópicas.

Devemos diferenciar os movimentos de massa de outros processos erosivos, que atuam por intermédio da água corrente, vento e geleiras. Assim movimentos de massa são movimentos de rochas ou partículas do solo pelas encostas, sob a influência da gravidade e sem a interferência da água corrente, vento ou gelo. A função dos movimentos de massa é transportar rochas ou materiais intemperizados das encostas, até aos vales, onde serão retransportados pelas águas correntes. Quando ocorrem ao longo das costas ou litorais (desmoronamentos em falésias), as ondas encarregar-se-ão de os carregar.

\section{CLASSIFICAÇÃO DOS MOVIMENTOS DE MASSA}

Há várias formas de classificar os movimentos de massa, porém as duas mais comuns são as que os classificam em rápidos e lentos ou os que envolvem rochas ou material intemperizado (solo e regolito). Os movimentos de massa rápidos são os desmoronamentos, deslizamentos ou escorregamentos e avalanchas. Os movimentos de massa lentos são o creep e a solifluxão.

Os desmoronamentos ou desabamentos, são movimentos repentinos de rochas ou solos em geral provocados por erosão na base das encostas, neste caso ocorrem principalmente em falésias (litorais) e áreas de mineração.
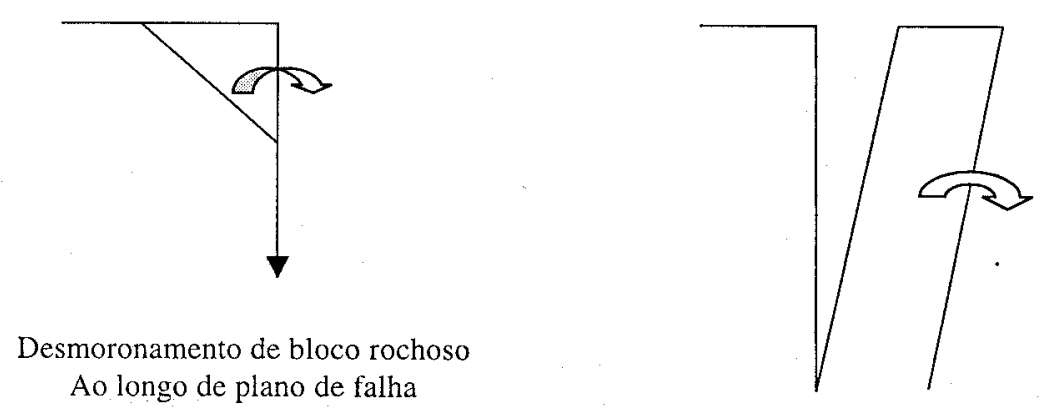

Desmoronamento do regolito devido a Stress das juntas do relevo 
Os deslizamentos, que quando em pequena escala os classificamos de escorregamentos, são os movimentos mais comuns no nosso país e em particular na região Sudeste. Ocorrem principalmente na estação chuvosa (entre dezembro e março), quando o solo fica encharcado pela água das chuvas que percola até determinada profundidade e encontra um substato impermeável que a impede de continuar se infiltrando e faz com que a parte superior atinja o limite de fluidez e deslize pela vertente. $\mathrm{O}$ deslizamento ocorre principalmente em vertentes antrópicas (Cortes em estradas) ou áreas de colúvio, isto é, materiais que em períodos passados desceram da encosta e se acomodaram na base ou na superfície da vertente e são facilmente remobilizados uma vez que entre eles e o material formado na própria vertente se forma um hiato ou plano de escorregamente que a qualquer momento pode movimentar-se novamente. A principal causa dos deslizamentos deriva da gravidade, mas é também conseqüência da infiltração da água que torna as forças que causam os movimentos excedam as que tendem a resistir a eles.

Movimentos lentos - Estes processos embora não chamem tanta atenção como os rápidos e só movimentem o solo ou regolito poucos milímetros por ano, não causando desastres, são muito importantes para o desenvolvimento da paisagem. Creep ou rastejamento - E um movimento lento do solo superficial, geralmente imperceptível, exceto para observações de longa duração. Este movimento é maior próximo da superfície, diminuindo com a profundidade até tornar-se nulo. Existem aparelhos que podem mensurar este movimento, porém geralmente se observa por rachaduras em muros, fendas nas estradas, inclinação de postes etc.

Solifluxão - A solifluxão é um deslizamento muito lento que vai até ao limite de penetração das águas de infiltração, muitas vezes o material fica tão encharcado que se comporta como lama e o solo desliza sobre uma camada impermeável existente a alguma profundidade. No Sudeste é comum onde os índices de pluviosidade são muito elevados, principalmente na região da RioSantos e subida da Serra do Mar.

Resumo: As vertentes são os elementos principais da superfície terrestre e é muito importante para geógrafos que se dedicam ao estudo da geomorfologia entendê-las nos seus vários aspectos: formas das vertentes, processos de erosão e intemperismo nelas atuantes.

Pode-se definir a vertente como um elemento da superfície terrestre inclinado em relação à horizontal, tendo deste modo um gradiente e uma orientação no espaço. Há vários objetivos no estudo das vertentes. Para o geomorfólogo, elas são unidades da superfície da Terra fundamentais para explicar a evolução do relevo.

Os estudos das vertentes não interessam apenas aos geógrafos da disciplina geomorfologia, mas também aos engenheiros, agrônomos e outros profissionais que lidam com agricultura, mineração ou atividades afins. Contudo cada um destes profissionais só se preocupa com um aspecto particular das vertentes. O geomorfólogo é o único que tem uma visão abrangente de todos os aspectos das vertentes.

Abstract: Hillslopes are the basic elements of all landscapes and is important for the students of geomorphology to appreciate how important they are in all aspects of the discipline. Is fundamental to geomorphology to understand forms and natural processes acting on slope facets which form almost the whole of the earth's land surface

We may define a hillslope as an element of the earth's surface inclined to the horizontal. Thus a slope processes a gradient and an orientation in space What are the aims of hillslope studies?. To geomorphologists, hillslopes are basic landscape units and so they are fundamental to any explanation of landscape development, thus, simply describe and explain hillslopes evolution.

However, hilslope studies have a much wider relevance than landscape explanation alone. Civil engineers involved with construction projects are constantly concerned with hillslope. Road gradients must not exceed acceptable standards, important question of slope stability. Landslides on embankments and cuttings shall be avoided. Agriculture on hillslopes is that mechanization is more difficult and soil erosion by flowing water is more acute, as slopes get steeper. However Engineering and agriculture sciences tend to confine their attention to specific properties of slope types. Geomorphologists are interested in ali kind of slopes, because their studies are the core of geomorphology.

\section{BIBLIOGRAFIA}

FINLAYSON, Brian \& STATHAM, Ian. 1986 Hillslope Analysis. London: Butterworth.

GUERRA, Antonio Teixeira. 1969 Dicionário Geológico-Geomorfológico. Rio de Janeiro: IBGE, $3^{\text {a }}$ Edição

INNIS, D. Q. Canada, a Geografic study. Toronto, McGraw-Hill Company, 1976

JACKSON, I. J. 1977 Climate, water and agriculture in the tropics. Harlow, Essex, U.K. Longman house.

MITCHELL, Colin. 1973 Terrain Evaluation London: Longman. 